\title{
Biointerface-Engineered DNA-Inspired Gold Nanoparticles for Colorimetric Biosensing of Heavy Metals
}

\author{
Zhiyu He ${ }^{1}$, Huiling Yin ${ }^{1}$, Chia-Chen Chang ${ }^{2}$, Guoqing Wang ${ }^{1}$, and Xingguo Liang ${ }^{1}$ \\ ${ }^{1}$ Ocean University of China \\ ${ }^{2}$ Chang Gung University
}

July 2, 2020

\begin{abstract}
The contamination of heavy metals (e.g., $\mathrm{Hg}, \mathrm{Pb}, \mathrm{Cd}$ and $\mathrm{As}$ ) poses great risks to environment and human health. Rapid and simple detection of heavy metals of considerable toxicity in low concentration levels is an important task in biological and environmental analysis. Among the many convenient detection methods for heavy metals, DNA-inspired gold nanoparticles (AuNPs) (DNA-AuNPs) have been becoming a well-established approach, in which assembly/disassembly of AuNPs serves for colorimetric signaling of the recognition event between DNA and target heavy metals at the AuNP interface. This review focuses on the recent efforts of employing DNA to manipulate the interfacial properties of AuNPs, and summarizes the recent advances in the colorimetric detection of heavy metals. Beginning with the introduction of the fundamental aspects of DNA and AuNPs, three main strategies of constructing DNA-AuNPs with DNA binding-responsive interface are discussed, namely, crosslinking, electrostatics, and base pair stacking. Then, recent achievements in colorimetric biosensing of heavy metals based on the interfacial manipulation of DNA-AuNPs are surveyed and compared. Finally, conclusions and perspectives on the futuristic directions in the field are provided, including the evaluation of the pros and cons of the three strategies, with an expectation of providing a reference for researchers who works in the related field. It is also suggested that manipulation of the interface of DNA-AuNPs represent enormous potential in the pursuit of colorimetric biosensors for a range of analytes of interest.
\end{abstract}

\section{Hosted file}

Manuscript_He_BTJ.docx available at https://authorea.com/users/338897/articles/465533biointerface-engineered-dna-inspired-gold-nanoparticles-for-colorimetric-biosensing-ofheavy-metals 